\title{
Emergence agitation in pediatric anesthesia: current features
}

\author{
Leopoldo Muniz da Silva, ${ }^{1}$ Leandro Gobbo Braz, ${ }^{2}$ Norma Sueli Pinheiro Módolo ${ }^{3}$
}

\begin{abstract}
Objective: Postoperative agitation in children is a well-documented clinical phenomenon with incidence ranging from $10 \%$ to $67 \%$. There is no definitive explanation for this agitation. Possible causes include rapid awakening in unfamiliar settings, pain (wounds, sore throat, bladder distension, etc.), stress during induction, hypoxemia, airway obstruction, noisy environment, anesthesia duration, child's personality, premedication and type of anesthesia. The purpose of this paper is to discuss the possible causes of postoperative agitation in children, providing a foundation for better methods of identifying and preventing this problem.
\end{abstract}

Sources: MEDLINE and PubMed were searched using the following words: emergence, agitation, incidence, etiology, diagnosis, treatment, children, pediatric, anesthesia.

Summary of the findings: This study includes a review of potential agitation trigger factors and a proposal for a standardized diagnostic score system, in addition to measures to improve prevention and treatment.

Conclusion: No single factor can identified as the cause of postoperative agitation, which should therefore be considered a syndrome made up of biological, pharmacological, psychological and social components, and which anesthesiologists and pediatric intensive care specialists should be prepared to identify, prevent and intervene appropriately as necessary.

J Pediatr (Rio J). 2008;84(2):107-113: Agitation on emergence, incidence, etiology, treatment, pediatric anesthesia, children.

\section{Introduction}

Postoperative agitation, also referred to as emergence delirium in international literature, is a well-documented clinical phenomenon, particularly in children. It is characterized by confusion mental, irritability, disorientation, inconsolable crying, and increased recovery time in the post anesthesia recovery room, increasing parents' concern and anxiety with respect to the clinical condition of their children. It can also lead to lost intravenous catheters, and disconnected cables and monitoring instruments.
It is during the first 30 minutes after emergence that the greatest incidence of agitation is observed, and duration is generally limited and recovery spontaneous. However, prolonged episodes of agitation lasting for up to 2 days have been described. ${ }^{1}$

There is no definitive explanation for emergence agitation. Many different causes have been suggested, such as rapid return of consciousness in an unfamiliar environment, the presence of pain (wounds, sore throat, bladder distension, etc.), stressful induction, airway obstructions, a noisy

1. Médico. Departamento de Anestesiologia, Faculdade de Medicina, Universidade Estadual Paulista (UNESP), Botucatu, SP, Brazil.

2. Doutor. Professor assistente, Departamento de Anestesiologia, Faculdade de Medicina, UNESP, Botucatu, SP, Brazil.

3. Professora adjunta, Departamento de Anestesiologia, Faculdade de Medicina, UNESP, Botucatu, SP, Brazil.

No conflicts of interest declared concerning the publication of this article.

Suggested citation: da Silva LM, Braz LG, Módolo NS. Emergence agitation in pediatric anesthesia: current features. J Pediatr (Rio J). 2008;84(2):107-113.

Manuscript received Oct 15 2007, accepted for publication Nov 212007.

doi:10.2223/JPED.1763 
environment, the duration of anesthesia, the child's personality, anesthetic premedication and the anesthetic technique used. ${ }^{2}$ The difficulty with establishing etiology explains the major variation in the prevalence rates reported in the literature, which vary from 10 to $67 .^{3-5}$

Many studies have used different measurement scales and definitions, making it difficult to compare studies in terms of incidence rates, risk factors and techniques for the control and prevention of postoperative agitation.

The authors comment that 16 comparative scales and two visual analogue scales have been created in order to assess emergence agitation. The criticism of these scales is that they are deficient in two aspects: psychometric assessment and content. Behavior such as crying, agitation and failure to co-operate, which are included in these scales, are not specific to agitation and are common to children who are in pain, hungry, scared or anxious. Furthermore, some of these scales were developed for adolescents and are inappropriate for school age and preschool children. ${ }^{6}$

As a response to this, the Pediatric Anesthesia Emergence Delirium (PAED) scale was developed with the objective of minimizing errors in the clinical assessment of agitation in children. ${ }^{7}$ This scale is made up of five items:

1) the child makes eye contact with the caregiver;

2) the child's actions are purposeful;

3) the child is aware of his/her surroundings;

4) the child is restless;

5) the child is inconsolable.

Items 1,2 and 3 are scored from 4 to 0 , where $4=$ not at all; 3 = just a little; 2 = quite a bit; $1=$ very much; $0=$ extremely, while items 4 and 5 , are scored from 0 to 4 , where 0 = not at all; 1 = just a little; 2 = quite a bit; 3 = very much; and $4=$ extremely.

Once the answers to each item have been converted into scores, they are summed, with the degree of agitation corresponding to the total score; the higher the score, the more agitated the child.

Although the PAED scale has proven useful and reliable, ${ }^{8}$ certain limitations have been identified, the principal of which is the difficulty in differentiating postanesthetic agitation from the symptoms of postoperative pain. ${ }^{7,8}$ Nevertheless, there is agreement that the use of the PAED scale is useful for improving the methodology of investigations into this area, particularly when postoperative pain has been ruled out as the cause of postoperative agitation. Challenges remain, related to the basic definitions and the need for accurate clinical instruments in order to diagnose and assess emergence agitation. $^{8}$
It is possible that the adoption of an age-based pain scale in combination with the PAED scale could be useful for defining diagnosis and assessment of emergence agitation.

\section{Factors linked with emergence agitation}

A range of factors may have an impact on the postoperative behavior of patients, as will be described below.

Age

The greatest incidence of agitation, after anesthesia with sevoflurane, is observed in preschool age children, compared with school-age children. Other studies have confirmed these results and, since then, the group that has received most research attention is that from 2 to 4 years of age. ${ }^{7-9}$ The cause of the increased incidence in this group appears to be that their emotional lability is exacerbated when faced with a stressful situation in an unfamiliar environment, in addition to the physiological condition of the hippocampus, which is still immature at this age. ${ }^{10}$

Psychological, social and environmental factors related to the operation

Younger children, those with impulsive and emotional behavior, those who are less sociable and whose parents are more anxious, appear to be more prone to developing this clinical phenomenon. ${ }^{5,11}$ When children are separated from their parents and sent to the operating room alone, this is traumatic and increases the risk of emergence agitation. ${ }^{12}$ Experimental research has demonstrated that separating mother rats from their young during the preoperative period triggered postoperative agitation. ${ }^{13}$

High scores on preoperative anxiety scales are predictive of adverse postoperative events, such as emergence agitation, or even behavioral changes during the postoperative period. A study of 791 children demonstrated that the risk of emergence agitation symptoms appearing increases by $10 \%$ for each increase of 10 points on the preoperative anxiety assessment score. ${ }^{14}$

Although countless studies have assessed the effect of parents being present on the quality of anesthetic induction, there is no consensus in the literature on whether this is an independent causal factor of the occurrence of postoperative agitation or merely a bias. No relationship was observed between psychosocial and behavioral factors when these were compared in terms of postoperative agitation. However, in that study, a standardized agitation scale was not used, being based on an observational analysis of the event, and the sample size was small. ${ }^{9}$

Risk factors for the occurrence of agitation had been assessed and no association was detected with the presence or absence of parents in the anesthetic recovery room. Agitation appears to primarily reflect a partially conscious process, 
in which the presence of parents does not have any significant impact on the behavior of the child. Analyses have also been made of the relationship between parents' anxiety, children's behavioral history and sleep disorders and postoperative agitation. It was concluded that children who exhibit frequent tantrums and those who suffer traumatic separation from their parents on the way to the operating room, tend to exhibit postoperative agitation more frequently, but without exhibiting long term psychological consequences. ${ }^{15} \mathrm{Nev}$ ertheless, even if the presence of parents is not a definitive protective factor against agitation, it makes the recovery room environment less hostile, transmitting greater safety and comfort to the child.

There were reports ${ }^{16}$ of negative consequences for the long-term behavior of children who have been subjected to anesthesia, and the relationship between postoperative agitation and behavioral changes over the long term was investigated, and no cause-and effect relationship could be detected. ${ }^{14}$

\section{Postoperative pain}

Postoperative pain has been one of the principal confounding factors when analyzing trigger factors for emergence agitation. In many studies, the use of preemptive analgesia resulted in a significant reduction in emergence agitation. The occurrence of agitation has been observed to be reduced when intravenous ketorolac has been used intraoperatively in otorhinolaryngological surgical procedures of short duration where the peak of the pharmacological agent's analgesic effect was after emergence. ${ }^{17}$ Nevertheless, even when postoperative pain is treated effectively or even absent (anesthetic procedures used for magnetic resonance imaging), postoperative agitation may still occur. Two groups of patients who underwent volatile anesthesia with sevoflurane for non-surgical procedures were studied. The control group exhibited an emergence agitation incidence of $47 \%$ and, in a group given dexmedetomidine during the operation, this was just $4.8 \% .{ }^{18}$ furthermore, emergence agitation has been observed in patients given a general anesthetic who had received caudal blockades, effectively providing analgesia. ${ }^{19}$

Therefore, postoperative pain appears to be an aggravating factor, and its behavioral manifestations may confound an emergence agitation diagnosis. However, it does not appear to be an independent etiologic factor, since even patients free from pain can exhibit agitation, making it a clinical phenomenon that remains irrespective of postoperative pain. Nevertheless, it is recommended that postoperative pain be removed from the equation through the use of adequate analgesia for all patients who exhibit signs compatible with emergence agitation.

\section{Type of surgery}

Otorhinolaryngological surgical procedures, such as tonsillectomy, thyroidectomy and ophthalmological operations, appear to exhibit an increased incidence of agitation. ${ }^{11,20}$ It is speculated that the sensation of suffocation in otorhinolaryngological procedures may be responsible for these events; although scientific evidence indicating that this is a causative factor of agitation is scarce and inconsistent.

\section{Inhaled and intravenous anesthetics}

Many studies have been carried out to determine whether the appearance of emergence agitation could be related to anesthetic technique or to the anesthetic used. Since anesthesia depresses central nervous system inhibitory centers and causes imbalances in neurotransmitters such as serotonin and dopamine and acetylcholine, it too may contribute to the appearance of this adverse event.

Several authors have detected an increased incidence of the complication with inhaled general anesthesia using sevoflurane, when compared with halothane. ${ }^{21-23}$ Other inhaled anesthetics, such as desflurane and isoflurane, have also been linked with the occurrence of emergence agitation. ${ }^{11,24}$ Emergence agitation incidence rates of 50 to $80 \%$ have been observed when desflurane was being used. ${ }^{24}$

Emergence agitation was detected in 2/3 of patients who underwent myringotomy for ventilation tube placement under anesthesia with sevoflurane.

In response to these results, the authors stated that this pharmaceutical was contraindicated for anesthetic maintenance in cases where minimum effort is desired in order to avoid ventilation tube displacement and consequent compromise to the procedure. ${ }^{3}$

Adding nitrous oxide to anesthesia with sevoflurane reduces the minimum alveolar concentration (MAC) of sevoflurane, meaning that lower concentrations of the anesthetic can be used, thereby reducing the incidence of postoperative agitation. ${ }^{25}$

When compared with isoflurane, sevoflurane appears not just to increase the incidence of emergence agitation, but also to prolong the duration of that agitation, which is a problem that was detected in children maintained under anesthesia with sevoflurane, where the occurrence of the complication was $20 \%$, compared with an incidence of $7 \%$ when isoflurane was employed. ${ }^{26}$

One of the hypotheses offered to explain this increased incidence of emergence agitation when sevoflurane is used, is the low solubility of this agent in blood, when compared with halothane, promoting earlier emergence from anesthesia and emergence agitation. ${ }^{4,17}$ However, anesthesia with propofol also favors rapid emergence, but with lower agitation incidence rates than those observed with sevoflurane. ${ }^{27}$ Furthermore, gradually reducing the concentration of sevoflurane, resulting in more prolonged emergence, did not result in a reduction in the incidence of agitation associated with this agent. $^{28}$ 
Electroencephalographic changes caused by the effects of sevoflurane on the central nervous system have also been suggested as a possible causative agent of agitation. However, epileptiform activity was observed equally in patients with agitation and in patients who did not exhibit this phenomenon when anaesthetized with sevoflurane. ${ }^{29}$ furthermore, there are no scientific data confirming neurotoxic effects from the degradation products of sevoflurane and its interaction with other types of anesthetic medication in the emergence agitation phenomenon. ${ }^{1}$ On the other hand, sevoflurane, isoflurane and desflurane all induce similar electroencephalographic changes during anesthesia, which are different to those provoked by halothane. This fact might explain the low incidence of agitation when patients are anesthetized with halothane. ${ }^{29-31}$

However, other authors have observed that there was no significant difference between the use of sevoflurane and the use of halothane in the incidence of emergence agitation or behavioral changes during the postoperative period or sleep disorders in children. ${ }^{32}$

Thus, faced with this evidence, it is clear that inhaled anesthetics, particularly sevoflurane and desflurane, are potential trigger factors of emergence agitation, but that there is not yet any definitive explanation for the triggering cause.

\section{Anesthetic premedication and adjuvant drugs}

The literature is contradictory on whether premedication is capable of reducing the incidence of emergence agitation. The pharmaceutical most often used for child premedication is midazolam. Some authors have observed a reduction in preoperative anxiety, have found it easier to separate children from parents and have observed a reduction in agitation when midazolam is used as premedication, followed by sevoflurane as anesthetic. ${ }^{3}$ However, some authors have observed that emergence time was prolonged when midazolam was used. ${ }^{3,33}$

Combining midazolam with small doses of diazepam, for premedication, improved the quality of recovery, with reduced incidence of agitation after anesthesia with sevoflurane. ${ }^{34}$

However, other authors have found that children premeditated with midazolam exhibited increased incidence of emergence agitation than children who did not receive these pharmaceuticals, offering the anti-analgesic effects of midazolam as an explanation. Nevertheless, the process of selecting patients for that study involved no type of randomization, and the results should be analyzed with caution. ${ }^{12}$

Although there are contradictory results, the use of short-action medication, without residual effects after the end of surgery, is supported by the fact that it reduces preoperative anxiety which could cause emergence agitation. ${ }^{5}$

In the same manner, long-acting medication, such as oxycodone, used for premedication, reduced the incidence of the complication when anesthesia was achieved using halothane, but the protective effect was not observed when anesthesia was with sevoflurane. ${ }^{35}$

Other medications, used for premedication, have been analyzed for their potential to block the appearance of postoperative agitation. Although its degree of preoperative anxiety relief is similar to that of midazolam, melatonin exhibited a lower incidence of postoperative agitation or sleep disorders during 2 weeks' postoperative observation. ${ }^{36}$ Another pharmaceutical used as premedication, ketamine, at a dosage of $6 \mathrm{mg} / \mathrm{kg}^{-1}$ given orally, reduced the incidence of emergence agitation by $34 \%$ in children under anesthesia with desflurane for adenotonsillectomy. ${ }^{37}$

Comparing nalbuphine $\left(0.1 \mathrm{mg} / \mathrm{kg}^{-1}\right)$ with ketamine $(0.25$ $\left.\mathrm{mg} / \mathrm{kg}^{-1}\right)$, administered at the end of inhaled sevoflurane anesthesia to children aged 6 months to 8 years before cerebral magnetic resonance imaging, a lower incidence of post-emergence agitation was detected in the group of patients given nalbuphine. Agitation occurred more frequently in the control group. ${ }^{38}$

Adrenergic $\alpha_{2}$-agonists are being used in pediatrics with an ever widening range of indications, such as, for example, premedication, adjuvants for central and peripheral blockades, analgesic for intrathecal perfusion, and for the control of withdrawal symptoms and tolerance of other sedatives. We can add to this list the prevention and treatment of emergence agitation. ${ }^{39}$

Therefore, the use of $\alpha_{2}$-agonists for prevention of emergence agitation could be justified on the basis of the action of these pharmaceuticals in reducing secretion of noradrenaline from the locus ceruleos, facilitating release of inhibitory neurons, such a those of the gamma aminobutyric acid system. ${ }^{40,41}$ The incidence of agitation was compared in children on premedication with midazolam $\left(0.5 \mu \mathrm{g} / \mathrm{kg}^{-1}\right)$ and clonidine (at dosages or 2 and $4 \mu \mathrm{g} / \mathrm{kg}^{-1}$ ). The group given the larger dose of clonidine exhibited a statistically the lower incidence than the groups given lower doses of clonidine or midazolam, although this result does not enjoy consensus in the literature. ${ }^{42}$

In children anaesthetized with sevoflurane, administration of intravenous clonidine $\left(2 \mu \mathrm{g} / \mathrm{kg}^{-1}\right)$, as an adjuvant drug, reduced the incidence of emergence agitation. ${ }^{43,44}$ Other authors have compared the effectiveness of clonidine, at doses of 1 and $3 \mu \mathrm{g} / \mathrm{kg}^{-1}$, given caudally, together with bupivacaine $0.175 \%$, with intravenous clonidine at a dosage of 3 $\mu \mathrm{g} / \mathrm{kg}^{-1}$ in combination with sevoflurane for anesthesia. The authors concluded that clonidine, at a dose of $3 \mu \mathrm{g} / \mathrm{kg}^{-1}$ of body weight, prevents emergence agitation, irrespective of route of administration. Notwithstanding, this appears to occur with clonidine, given caudally at a dosage of $1 \mu \mathrm{g} / \mathrm{kg}^{-1}$ body weight. ${ }^{45}$ 
Tropisetron $\left(0.1 \mathrm{mg} / \mathrm{kg}^{-1}\right)$ and clonidine were compared, at a dose of $1.5 \mu \mathrm{g} / \mathrm{kg}^{-1}$ administered after anesthetic induction, to children being anaesthetized with sevoflurane for adenotonsillectomy. Tropisetron proved effective for reducing emergency agitation, but clonidine did not. ${ }^{46}$

Intravenous clonidine $\left(2 \mu \mathrm{g} / \mathrm{kg}^{-1}\right)$, administered after induction of anesthesia, reduced the incidence of emergence agitation, although there was greater postoperative somnolence, while no adverse cardiorespiratory events were observed. ${ }^{44}$

Using more selective $\alpha_{2}$-agonists, an agitation incidence of $4.8 \%$ was observed among patients given dexmedetomidine, at a dosage of $1 \mu \mathrm{g} / \mathrm{kg}^{-1}$ intravenously, compared with $47.6 \%$ in a placebo group, without detecting increases in emergence time or intraoperative hemodynamic repercussion. ${ }^{18}$

The administration of dexmedetomidine at dosages of 0.15 and $0.3 \mu \mathrm{g} / \mathrm{kg}^{-1}$ of body weight, after induction of anesthesia with sevoflurane, was compared with a placebo group. There was a reduced incidence of emergence agitation in both of the groups given dexmedetomidine, without causing any difference in emergence time. There was also no relationship between agitation during anesthetic induction and emergence agitation. ${ }^{47}$

Dexmedetomidine, used in continuous infusion at a dose of $0.2 \mu \mathrm{g} / \mathrm{kg}^{-1 /} \mathrm{h}^{-1}$, proved effective for reducing the incidence of emergence agitation after anesthesia maintained with sevoflurane. ${ }^{18}$ In a similar manner, it was effective for preventing this complication at a dosage of $0.5 \mu \mathrm{g} / \mathrm{kg}^{-1}$ body weight. ${ }^{48}$

Therefore, $\alpha_{2}$-agonists appear to be useful for reducing postoperative agitation in children.

\section{Conclusions}

In summary, no single factor in isolation could be identified as causing postoperative agitation, and the condition should be considered to be a syndrome with biological, pharmacological, psychological and social components and one which anesthetists should be prepared to identify and to prevent and to intervene appropriately when necessary.

For children, certain measures are recommendable in order to avoid or minimize the occurrence of postoperative agitation

- Wake the child in a silent environment, avoiding physical or verbal stimulation during transport to the post anesthesia recovery room, until the child is completely awake and able to perceive external stimuli.

- Maintain the child at normal body temperature with sufficient supplementary oxygen whenever there is a need.
- If necessary, administer analgesics if pain is suspected, such as dipyrone, tramadol and anti-inflammatories, or any other analgesic that may be indicated.

- Allow parents or whoever is accompanying the child to remain in the anesthetic recovery room, helping to reduce agitation. According to the current literature, $\alpha_{2}$-agonists appear to be the group of drugs most effective for preventing and treating this complication.

Post anesthetic agitation is a self-limiting phenomenon, and there is no evidence that these short episodes of agitation prejudice the recovery or behavior of children over the long term. Nevertheless, a turbulent recovery is unpleasant, in addition to being incompatible with good anesthetic practice. An agitated or crying child are factors that reduce parents' satisfaction with the anesthetic care received by their children.

\section{References}

1. Vlajkovic GP, Sindjelic RP. Emergence delirium in children: many questions, few answer. Anesth Analg. 2007;104:84-91.

2. Veyckemans F. Excitation phenomena during sevoflurane anaesthesia in children. Curr Op Anesthesiol. 2001;14:339-43.

3. Lapin SL, Auden SM, Goldsmith LJ, Reynolds AM. Effects of sevoflurane anaesthesia on recovery in children: a comparison with halothane. Paediatr Anaesth. 1999;9:299-304.

4. Welborn LG, Hannallah RS, Norden JM, Ruttimann UE, Callan CM. Comparison of emergence and recovery characteristics of sevoflurane, desflurane, and halothane in pediatric ambulatory patients. Anesth Analg. 1996;83:917-20.

5. Aouad MT, Nasr VG. Emergence agitation in children: an update. Curr Opin Anaesthesiol. 2005;18:614-9.

6. Heaman DJ, Mattle LF. Adolescent emergence excitement. AORN J. $1982 ; 35: 230-42$.

7. Sikich $\mathrm{N}$, Lerman J. Development and psychometric evaluation of the pediatric anesthesia emergence delirium scale. Anesthesiology. 2004;100:1138-45.

8. Scott GM, Gold JI. Emergence delirium: a re-emerging interest. Seminars in Anesthesia, Perioperative Medicine and Pain. 2006; 25:100-4.

9. Przybylo HJ, Martini DR, Mazurek AJ, Bracey E, Johnsen L, Cote $C J$. Assessing behaviour in children emerging from anaesthesia: can we apply psychiatric diagnostic techniques? Paediatr Anaesth. 2003;13:609-16.

10. Martini DR. Commentary: The diagnosis of delirium in pediatric patients. J Am Acad Child Adolesc Psychiatry. 2005;44:395-8. 
11. Voepel-Lewis T, Malviya S, Tait AR. A prospective cohort study of emergence agitation in the pediatric postanesthesia care unit. Anesth Analg. 2003;96:1625-30

12. Cole JW, Murray DJ, McAllister JD, Hirshberg GE. Emergence behaviour in children: defining the incidence of excitement and agitation following anaesthesia. Paediatr Anaesth. 2002;12: 442-7.

13. Arai YC, Ueda W, Al-Chaer ED. Pre-anesthetic maternal separation increases pups' locomotor behavior during emergence from anesthesia in rats. Acta Anaesthesiol Scand. 2004;48: 174-7.

14. Kain ZN, Caldwell-Andrews AA, Maranets I, McClain B, Gaal D, Mayes LC, et al. Preoperative anxiety and emergence delirium and postoperative maladaptive behaviors. Anesth Analg. 2004; 99:1648-54.

15. Tripi PA, Palermo TM, Thomas S, Goldfinger MM, Florentino-Pineda I. Assesment of risk factors for emergence distress and postoperative behavioral changes in children following general anaesthesia. Paediatr Anaesth. 2004;14: 235-40.

16. Eckenhoff JE, Kneale DH, Dripps RD. The incidence and etiology of postanesthetic excitement. A clinical survey. Anesthesiology $1961 ; 22: 667-73$.

17. Davis PJ, Greeberg JA, Genldeman M, Fertal K. Recovery characteristics of sevoflurane and halothane in preschool-aged children undergoing bilateral myringotomy and pressure equalization tube insertion. Anesth Analg. 1999;88:34-8.

18. Isik B, Arslan M, Tunga AD, Kurtipec O. Dexmedetomidine decreases emergence agitation in pediatric patients after sevoflurane anesthesia without surgery. Paediatr Anaesth. 2006; 16:748-53.

19. Weldon BC, Bell M, Craddock T. The effect of caudal analgesia on emergence agitation in children after sevoflurane versus halothane anesthesia. Anesth Analg. 2004;98:321-6.

20. Galford RE.Problems in anesthesiology: approach to diagnosis. Boston, MA: Little, Brown \& Company. 1992. p. 3413.

21. Aono J, Ueda W, Mamiya K, Takemoto E, Manabe M. Greater incidence of delirium during recovery from sevoflurane anesthesia in preschool boys. Anesthesiology. 1997;87: 1298-300.

22. Beskow A, Westrin P. Sevoflurane causes more postoperative agitation in children than does halothane. Acta Anaesthesiol Scand. 1999;43:536-41.

23. Cravero J, Surgenor S, Whalen K. Emergence agitation in paediatric patients after sevoflurane anaesthesia and no surgery: a comparison with halothane. Paediatr Anaesth. 2000;10: 419-24.

24. Cohen IT, Hannallah RS, Hummer KA. The incidence of emergence agitation associated with desflurane anesthesia in children is reduced by fentanyl. Anesth Analg. 2001;93:88-91.

25. Shibata S, Shigeomi S, Sato W, Enzan K. Nitrous oxide administration during washout of sevoflurane improves postanesthetic agitation in children. J Anesth. 2005;19:160-3.

26. Bortone L, Ingelmo P, Grossi S, Grattagliano C, Bricchi C, Barantani D, et al. Emergence agitation in preschool children: double-blind, randomized, controlled trial comparing sevoflurane and isoflurane anesthesia. Paediatr Anaesth. 2006;16:1138-43.

27. Picard V, Dumont L, Pellegrini M. Quality of recovery in children: sevoflurane versus propofol. Acta Anaesthesiol Scand. 2000;44: 307-10.
28. Oh AY, Seo KS, Kim SD, Kim CS, Kim HS. Delayed emergence process does not result in a lower incidence of emergence agitation after sevoflurane anesthesia in children. Acta Anaesthesiol Scand. 2005;49:297-9.

29. Constant I, Seeman R. Inhalational anesthetics in pediatric anesthesia. Curr Opin Anaesthesiol. 2005;18:277-81.

30. Freye E, Bruckner J, Latasch L. No difference in electroencephalographic power spectra or sensory-evoked potentials in patients anaesthetized with desflurane or sevoflurane. Eur J Anaesthesiol. 2004;21:373-8.

31. Schwender D, Daunderer M, Mulzer S, Klasing S, Finsterer U, Peter K. Spectral edge frequency of the electroencephalogram to monitor "depth" of anaesthesia with sevoflurane or propofol. $\mathrm{Br}$ ] Anaesth. 1996;77:179-84.

32. Kain ZN, Caldwell-Andrews AA, Weinberg ME, Mayes LC, Wang SM, Gaal D, et al. Sevoflurane versus halothane: postoperative maladaptive behavioral changes: a randomized, controlled trial. Anesthesiology. 2005;102:720-6.

33. Viitanen $\mathrm{H}$, Annila P, Viitanen M, Tarkilla P. Premedication with midazolam delays recovery after ambulatory sevoflurane anesthesia in children. Anesth Analg. 1999;89:75-9.

34. Arai YC, Fukunaga K, Hirota S. Comparison of a combination of midazolam and diazepam and midazolam alone as oral premedication on preanesthetic and emergence condition in children. Acta Anaesthesiol Scand. 2005;49:698-701.

35. Murray DJ, Cole JW, Shrock CD, Snider RJ, Martini JA. Sevoflurane versus halothane: effect of oxycodone premedication on emergence behaviour in children. Paediatr Anaesth. 2002;12:308-12.

36. Samarkandi A, Naguib M, Riad W, Thalaj A, Alotibi W, Aldammas $F$, et al. Melatonin vs. midazolam premedication in children: a double-blind, placebo-controlled study. Eur J Anaesthesiol. 2005;22:189-96.

37. Kararmaz A, Kaya S, Turhanoglu S, Ozyilmaz MA. Oral ketamine premedication can prevent emergence agitation in children after desflurane anaesthesia. Paediatr Anaesth. 2004;14:477-82.

38. Dalens BJ, Pinard AM, Letourneau DR, Albert NT, Truchon RJ. Prevention of emergence agitation after sevoflurane anesthesia for pediatric cerebral magnetic resonance imaging by small doses of ketamine or nalbuphine administered just before discontinuing anesthesia. Anesth Analg. 2006;102:1056-61.

39. Mencía SB, López-Herce JC, Freddi N. Analgesia and sedation in children: pratical approach for the most frequent situations. J Pediatr (Rio J). 2007;83:S71-82:

40. Malviya S, Voepel-Lewis T, Ramamurthi RJ, Burke C, Tait AR. Clonidine for the prevention of emergence agitation in young children: efficacy and recovery profile. Paediatr Anaesth. 2006; 16:554-9.

41. Tobias JD, Berkenbosch JW, Russo P. Additional experience with dexmedetomidine in pediatric patients. South Med J. 2003;96: 871-5.

42. Tazeroualti N, De Groote F, De Hert S, De Villé A, Dierick A, Van der Linden $P$. Oral clonidine vs. midazolam in the prevention of sevoflurane-induced agitation in children. A prospective, randomized, controlled trial. $\mathrm{Br}$ ] Anaesth. 2007;98:667-71.

43. Fazi L, Jantzen EC, Rose JB, Kurth CD, Watcha MF. A comparison of oral clonidine and oral midazolam as preanesthetic medications in the pediatric tonsillectomy patient. Anesth Analg. $2001 ; 92: 56-61$.

44. Kulka PJ, Bressem M, Tryba M. Clonidine prevents sevoflurane-induced agitation in children. Anesth Analg. 2001; 93:335-8. 
45. Bock M, Kunz P, Schreckenberger R, Graf BM, Martin E, Motsch J. Comparison of caudal and intravenous clonidine in the prevention of agitation after sevoflurane in children. $\mathrm{Br}$ ] Anaesth. 2002;88:790-6.

46. Lankinen $U$, Avela R, Tarkkila P. The prevention of emergence agitation with tropisetron or clonidine after sevoflurane anesthesia in small children undergoing adenoidectomy. Anesth Analg. 2006;102:1383-6.

47. Ibacache ME, Munoz HR, Brandes V, Morales AL. Single-dose dexmedetomidine reduces agitation after sevoflurane anesthesia in children. Anesth Analg. 2004;98:60-3.
48. Guler G, Akin A, Tosun Z, Ors S, Esmaoglu A, Boyaci A. Single-dose dexmedetomidine reduces agitation and provides smooth extubation after pediatric adenotonsillectomy. Paediatr Anaesth. 2005;15:762-6.

Correspondence:

Norma Sueli Pinheiro Módolo

Departamento de Anestesiologia

Faculdade de Medicina de Botucatu - UNESP

Caixa Postal 530, Distrito de Rubião Júnior

CEP 18618-970 - Botucatu, SP - Brazil

E-mail: nmodolo@fmb.unesp.br 